\title{
Organ Procurement and Transplantation in Belgium
}

\author{
Olivier Detry, MD, PhD, ${ }^{1}$ Dominique Van Deynse, $\mathrm{RN},{ }^{2}$ Hans Van Vlierberghe, $\mathrm{MD}, \mathrm{PhD},{ }^{3}$ \\ and Jacques Pirenne, MD, PhD, ${ }^{4}$ on behalf of the Belgian Transplantation Society (BTS)
}

\section{SOLID ORGAN TRANSPLANTATION IN BELGIUM: HISTORY AND MILESTONES}

Belgium, a federal country of 11 million inhabitants (as of 2016), has been very active in the field of transplantation. Clinical transplantation activities were initiated in the early 1960s with the first, living and deceased, kidney transplantations. $^{1-5}$ During these pioneering years, Belgium was recognized for carrying out the first deceased organ donation after the diagnosis of brain death in 1963 (by Pr Alexandre, University of Leuven), ${ }^{1,4}$ and the first long-term survival (10 months) after lung transplantation in 1968 (Pr Derom, Ghent University). ${ }^{6}$ The Belgian transplant centers were directly involved in establishing Eurotransplant in 1967 under the auspices of Pr Van Rood, from the University of Leiden (The Netherlands). Those efforts included also the implementation of a database for kidney transplant candidates and organ donors that improved HLA matching. Fifty years later, Belgium is still an active member of the Eurotransplant Foundation, a nonprofit organization based in Leiden, which is currently in charge of organ allocation in 8 European countries for a total population of nearly 135 million inhabitants. ${ }^{7}$

\section{THE BELGIAN TRANSPLANTATION LAW}

The first version of the Belgian transplantation law was published in 1986 and has been slightly modified since. ${ }^{8}$ For deceased donation (DD), the Belgian legislator decided for an "opting-out" system, with the possibility for the Belgian citizens to register "for" or "against" organ donation. This law does not explicitly define the criteria to be used to diagnose donor death but mentions that the criteria should be

Received 13 December 2016. Revision received 16 December 2016. Accepted 8 May 2017.

${ }^{1}$ Department of Abdominal Surgery and Transplantation, CHU Liege, University of Liege, Liege, Belgium.

${ }^{2}$ Department of Abdominal Surgery and Transplantation, Cliniques Universitaires St Luc (UCL), Brussels, Belgium.

${ }^{3}$ Department of Gastroenterology and Hepatology, Ghent University Hospital, Ghent, Belgium.

${ }^{4}$ Abdominal Transplant Surgery Department, UZ Gasthuisberg, University of Leuven (KUL), Leuven, Belgium.

The authors declare no funding or conflicts of interest.

Correspondence: Olivier Detry, MD, PhD, Department of Abdominal Surgery and Transplantation, CHU Liege, Sart Tilman B35, B4000 Liege, Belgium. (olivier. detry@transplantation.be).

Copyright @ 2017 Wolters Kluwer Health, Inc. All rights reserved.

ISSN: 0041-1337/17/10109-1953

DOI: 10.1097/TP.0000000000001866 based on the latest medical knowledge and techniques. Therefore, in addition to donation after brain death, controlled and uncontrolled donations after circulatory death (DCD) are legal in Belgium. Donor death must be certified by 3 independent medical doctors excluding those involved in organ procurement, transplantation, or the care of the recipients. The Belgian transplant law also guarantees anonymity and the absence of contacts between the families of donors and recipients. Access to the Belgian transplant waiting lists is limited to the citizens of Eurotransplant countries, or to candidates not from Belgium who have been officially registered as residents in a Eurotransplant country for a period of more than 6 months. By renewed contracts, the Belgian authorities have delegated the organization of organ allocation based on medical parameters to Eurotransplant. Allocation rules are defined by Eurotransplant and regularly updated per the advice of organ-specific committees with final approval by the Belgian authorities. The Belgian transplantation law also allows organ procurement from informed live adult donors. Of note, the Belgian transplantation law forbids any financial remuneration for deceased or living organ donation.

\section{ORGANIZATION OF ORGAN PROCUREMENT AND TRANSPLANTATION IN BELGIUM}

All 7 university hospitals in addition to 1 nonuniversity hospital (OLV Hospital, Aalst, for heart transplants only) have been accredited to perform deceased and living transplantation in Belgium. All hospitals without transplantation activity are educated to identify potential DD. In fact, two thirds of the procured DD in Belgium are referred by hospitals without transplantation activities. All transplantation centers must report annually on their transplantation activities (types, and numbers, of donors and transplantations), but reporting of outcomes is not mandatory. The Belgian Transplantation Society (BTS) was created in 1993 as the scientific organization dealing with organ transplantation in Belgium. Members of the BTS include clinicians, scientists, transplant coordinators, clinical and research transplant nurses, and allied health professionals involved in organ transplantation. ${ }^{9}$ The board of the BTS is composed of representatives from all the transplantation centers, and its president serves for a 2-year period. The BTS organizes an annual scientific meeting and supports multicenter studies. Committees are responsible for organ-specific issues, and there is 1 procurement committee. In addition, there are 2 professional sections, the transplant coordinator and the transplant nurse sections.

In addition to the BTS, the Belgian Transplantation Council has been established as an advisory board to the Ministry 
TABLE 1.

Transplantation activity in Belgium ${ }^{7}$

\begin{tabular}{|c|c|c|c|c|c|c|c|c|c|c|}
\hline Deceased donor & 2007 & 2008 & 2009 & 2010 & 2011 & 2012 & 2013 & 2014 & 2015 & 2016 \\
\hline Kidney & 449 & 442 & 428 & 404 & 474 & 480 & 437 & 414 & 471 & 453 \\
\hline Heart & 72 & 75 & 68 & 68 & 76 & 77 & 75 & 82 & 82 & 70 \\
\hline Lung & 93 & 82 & 90 & 114 & 111 & 129 & 101 & 104 & 115 & 129 \\
\hline Liver & 229 & 199 & 208 & 207 & 255 & 250 & 248 & 221 & 247 & 255 \\
\hline Split liver & 11 & 18 & 12 & 3 & 7 & 0 & 2 & 10 & 4 & 1 \\
\hline Pancreas & 19 & 19 & 13 & 22 & 18 & 13 & 8 & 11 & 9 & 11 \\
\hline Intestine & 3 & 2 & 1 & 0 & 4 & 2 & 0 & 4 & 0 & 0 \\
\hline Pancreatic islets & 13 & 12 & 12 & 7 & 15 & 19 & 9 & 7 & 11 & 12 \\
\hline Total & 889 & 849 & 832 & 825 & 960 & 970 & 880 & 853 & 939 & 931 \\
\hline Living donor & 2007 & 2008 & 2009 & 2010 & 2011 & 2012 & 2013 & 2014 & 2015 & 2016 \\
\hline Kidney & 42 & 45 & 49 & 49 & 40 & 57 & 63 & 67 & 57 & 67 \\
\hline Domino liver & 1 & 0 & 2 & 0 & 2 & 2 & 0 & 2 & 1 & 3 \\
\hline Liver & 26 & 13 & 23 & 33 & 35 & 30 & 42 & 38 & 32 & 43 \\
\hline Total & 69 & 58 & 74 & 82 & 77 & 89 & 105 & 107 & 90 & 113 \\
\hline Grand Total & 958 & 907 & 906 & 907 & 1037 & 1059 & 985 & 960 & 1029 & 1044 \\
\hline
\end{tabular}

of Health and Social Affairs. The composition of this council includes not only transplantation physicians but also intensive care physicians, ethicists, and representatives of the national health insurance system.

\section{PROCUREMENT ACTIVITY}

The large majority of solid organ transplantations performed in Belgium are DD transplants (Table 1). Thanks to one of the world's highest DD rates (between 24 and 30 deceased donors per million inhabitants from 2006 to 2015, 28.4 in 2016), living donation contributes only to a smaller portion to the overall transplantation rates $(12.8 \%$ for kidneys, $15.2 \%$ for livers in 2016) and serves in part patients without possible access to the deceased donor waiting list. Over the past 10 years, the percentage of controlled DCD to the DD pool has substantially increased to reach $29 \%$ in 2016 (Figure 1). ${ }^{10,11}$ In contrast, uncontrolled DCD is rarely performed in Belgium. A working group within the Belgian Transplantation Council has established national guidelines on DCD donations that have been approved by the government and the national ethical committee. ${ }^{12}$

In 2002, Belgium followed the Netherlands and became the second country to legalize physician-assisted death and

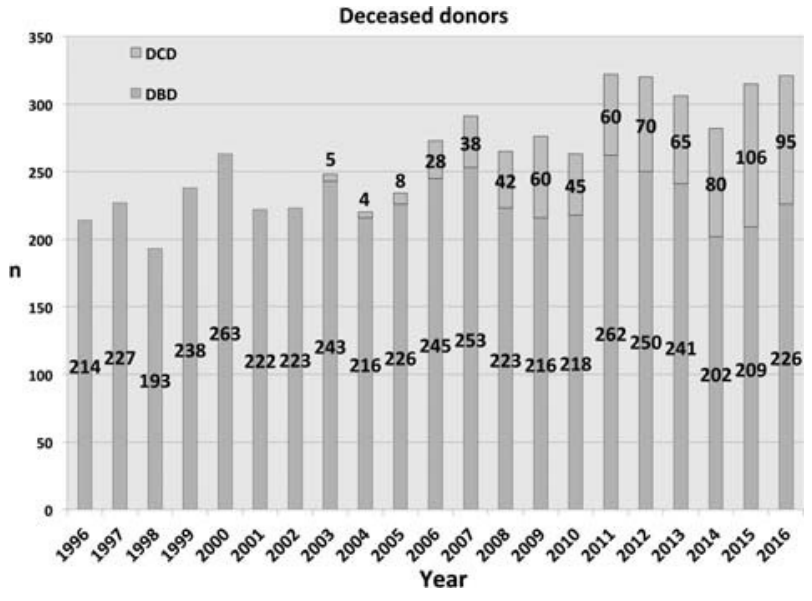

FIGURE 1. Yearly number of deceased organ donors in Belgium (1996-2016). euthanasia in highly selected patients under strict medical and legal conditions. In 2005, 1 patient, for whom a request for euthanasia had been accepted per the strict medical and legal rules, spontaneously expressed her will of after-death DCD. The possibility was urgently and meticulously discussed by the ethics committee at the University Hospital of Antwerp (Pr Ysebaert). This committee agreed to proceed with organ donation under the strict condition that the 2 procedures, euthanasia and DCD, would stay separated, that is, that the donation would only take place after declaration of the patient's death and that the medical teams involved would be independent. Since this first case, the number of DCDs after euthanasia has slowly increased (Figure 2). ${ }^{13,14}$ As required by the Belgian transplantation law, these DCD organs are allocated per Eurotransplant rules and are now officially classified as DCD class 5 by the BTS and Eurotransplant. ${ }^{15,16}$

\section{WAITING LISTS}

In 2016, 107 patients died waiting for DD organs in Belgium (45 for liver, 33 for kidney, 20 for heart, 7 for lung, and 2 for pancreas). By December 31, 2016, 1275 patients had been listed for transplantation (175 for liver, 796 for kidney, 117 for heart, 122 for lung, and 65 for pancreas).

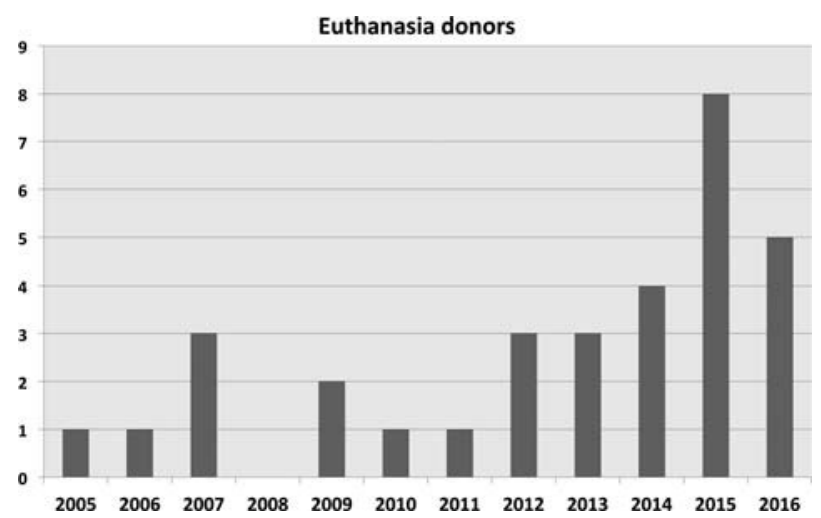

FIGURE 2. Yearly number of euthanasia organ donors in Belgium (2005-2016). 


\section{TRANSPLANTATION ACTIVITY}

A total of 1044 transplantations were performed in 8 Belgian transplant centers in 2016 (Table 1). There are 7 centers with an active program of cardiac transplantation, 4 with lung, 7 with kidney and/or pancreas, 6 with liver, and 2 with intestine transplantation ${ }^{17}$ (data from eurotransplant.org). One face transplant has been performed at a university hospital in Ghent in 2011. ${ }^{18}$

\section{CHALLENGES AND FUTURE OF ORGAN TRANSPLANTATION IN BELGIUM}

To serve the Belgian population better, transplant professionals and the BTS are eager to increase both volume and quality of available grafts. Living-related donor programs are encouraged, especially for kidney transplantation. A national program on living donor kidney exchange has been launched with the first cases performed in 2014, potentially increasing the availability of kidneys for transplantation. Machine perfusion of DCD kidneys still needs financial coverage from the national health insurance system, and some Belgian centers are involved with research initiatives on machine perfusion of liver grafts. The procurement of DCD organs originating from euthanasia patients may allow to increase the availability of kidneys, pancreata, livers, and lungs ${ }^{19}$ with the potential of hearts once future basic and clinical research has confirmed favorable outcomes. ${ }^{20}$

\section{ACKNOWLEDGMENTS}

The authors acknowledge the efforts and motivation of all members of the BTS. The members of the 2016-2018 BTS board are Olivier Detry (ULg, President), Olivier Van Caenegem (UCL, Secretary), Nicolas Meurisse (ULg, treasurer), Jacques Pirenne (KUL, former president), Anja Geerts (UG), Daniel Jacobs-Tuleneers-Thevissen (VUB), Alain Lemoine (ULB), Valerio Lucidi (ULB), Michel Mourad (UCL), Patrick Evrard (UCL), Caren Randon (UG), Geert Roeyen (UA), Ivo Haentjens (Transplant coordinator section), Dominique Van Deynse (Transplant coordinator section), Karl M Wissing (VUB), Daniel Abromowicz (UA, for the Be-KPAC), Johan Van Cleemput (KUL, for the Be-ThAC), Dirk Van Raemdonck (KUL, for the Be-ThAC), Diethard Monbaliu (KUL, for the Be-OPC), Carine Breunig (President BTSN), and Mathilde Dehairs (Secretary, BTSN).

\section{REFERENCES}

1. Squifflet JP. The history of transplantation at the Catholic University of Louvain Belgium 1963-2003. Acta Chir Belg. 2003;103(Suppl 1):10-20.

2. Lejeune G, Limet R, Meurisse M, et al. History of solid organ transplantation at the University of Liège. Acta Chir Belg. 2003;103(3 Spec No): 32-6.

3. De Pauw L. Organ transplantation pioneers at the "Université Libre de Bruxelles." Acta Chir Belg. 2003;103(3 Spec No):25-27.

4. Coosemans W. Renal transplantation at K.U. Leuven. Acta Chir Belg. 2003;103(3 Spec No):21-4.

5. Ysebaert D. History of transplantation at the University Hospital of Antwerp. Acta Chir Belg. 2003;103(3 Spec No):37-8.

6. Hesse UJ, de Hemptinne B, Derom F. History of transplantation at the University Hospital of Ghent Belgium 1965-2002. Acta Chir Belg. 2003:103(Suppl 1):28-31.

7. Eurotransplant. Eurotransplant Web site. http://www.eurotransplant.org/ cms/. Updated 2017. Accessed May 2, 2017.

8. Squifflet AC. Prélèvement et Transplantation D'organes. Droits National, Européen et International Face à la Pénurie. Anthemis: Limal, Belgium; 2016.

9. Belgian Transplantation Society. Belgian Transplantation Society Web site. http://www.transplant.be/. Updated 2016. Accessed December 15, 2016.

10. Detry O, Troisi R. Organ donation in Belgium 2009: $20 \%$ of donation after cardiocirculatory death. Transplant Proc. 2010;42:4365.

11. Squifflet JP. Why did it take so long to start a non-heart-beating donor program in Belgium? Acta Chir Belg. 2006;106:485.

12. Belgian Transplantation Council, Belgian Transplantation Society. Opinion no. 63-draft protocol "Donation after Circulatory Death" (DCD). Service Public Federal Web site. https://www.health.belgium.be/fr/node/28836. Published online October 12, 2015. Accessed May 2, 2017.

13. Ysebaert D, Van Beeumen G, De Greef K, et al. Organ procurement after euthanasia: Belgian experience. Transplant Proc. 2009;41: 585-586.

14. Detry O, Laureys S, Faymonville ME, et al. Organ donation after physicianassisted death. Transpl Int. 2008;21:915.

15. Detry O, Le Dinh $H$, Noterdaeme $T$, et al. Categories of donation after cardiocirculatory death. Transplant Proc. 2012;44:1189-1195.

16. Evrard P. Belgian Working Group on DCD National Protocol. Belgian modified classification of Maastricht for donors after circulatory death. Transplant Proc. 2014;46:3138-3142.

17. Ceulemans LJ, Monbaliu D, De Roover A, et al. Belgian multicenter experience with intestinal transplantation. Transpl Int. 2015;28: 1362-1370.

18. Roche NA, Vermeersch HF, Stillaert FB, et al. Complex facial reconstruction by vascularized composite allotransplantation: the first Belgian case. J Plast Reconstr Aesthet Surg. 2015;68:362-371.

19. Van Raemdonck D, Neyrinck A. Euthanasia patients should be accepted as organ donors in states with existing legislation. Ann Thorac Surg. 2016; 102:1787-1788.

20. Noterdaeme T, Detry $\mathrm{O}$, Hans MF, et al. What is the potential increase in the heart graft pool by cardiac donation after circulatory death? Transpl Int. 2013;26:61-66.
Fadi Issa, MRCS, DPhil ${ }^{1}$

\section{Single-cell RNA-seq Reveals New Types of Human Blood Dendritic Cells, Monocytes, and Progenitors}

Villani A-C, Satija R, Reynolds G, et al. Science. 2017; 356(6335).

esearch in immunology is often complicated by challenges in clear communication: when we publish our work, are we talking about the same cells? The field is often
Received 11 July 2017. Revision received 12 July 2017.

Accepted 13 July 2017

${ }^{1}$ Nuffield Department of Surgical Sciences, University of Oxford, John Radcliffe Hospital, Oxford, United Kingdom.

The author declares no funding or conflicts of interest.

Correspondence: Fadi Issa, MRCS, DPhil, Nuffield Department of Surgical Sciences, University of Oxford, John Radcliffe Hospital, Oxford OX3 9DU, United Kingdom. (fadi.issa@nds.ox.ac.uk).

Copyright (C) 2017 Wolters Kluwer Health, Inc. All rights reserved.

ISSN: 0041-1337/17/10109-1955

DOI: $10.1097 /$ TP.0000000000001890 